\title{
APORTES PARA LA COMPRENSIÓN DE LA HISTORIA DE LA EDAD MEDIA DESDE EL HORIZONTE DE LA UTOPÍA SOCIAL CRISTIANA ${ }^{1}$
}

\author{
Gerardo A. Martínez Z.
}

Universidad Santo Tomás

\section{Resumen}

Este artículo presenta una visión histórica de la utopía social cristiana en la Edad Media. Se pone de presente que la praxis social y religiosa conducida por la Iglesia institucional en ese periodo de tiempo está relacionada con una crisis u ocaso de la utopía social cristiana, entendida ésta como la búsqueda de una sociedad en la que impere la igualdad social y religiosa, que se rija por el principio de misericordia, y que esté abierta no sólo a los elegidos (como se sentía el pueblo judío), sino a todos los seres humanos, con especial predilección por los pobres, como primeros destinatarios del mensaje cristiano. Se presenta la Edad Media como un periodo de tiempo que se guió por una mentalidad religiosa y una praxis económica y social que ocultó la utopía, la cual resurgió en el humanismo y en algunas prácticas evangelizadoras en el Nuevo Mundo.

\section{Palabras clave}

Utopía social cristiana, mentalidad, historia, crisis, Edad Media.

\section{Abstract}

This article presents a historical vision of the Christian Social Utopia in the Middle Ages. It states that the religious and social praxis carried out by the Institutional Church in that period of time is related to a crisis or decline of the Christian Social utopia

\footnotetext{
El titulo está inspirado en uno de los capítulos de mi tesis "La utopía social cristiana en las reducciones jesuíticas del Paraguay”, presentada para optar al título de Licenciado en Filosofía y Letras en la Facultad de Filosofía de la Universidad Santo Tomás, Bogotá.
} 
understood as the search for a society in which the religious and social equality prevails, that is governed by the principle of compassion and that is open not only to the chosen ones (just like the Jewish felt), but to all Human beings, especially the poor ones as target of the Christian Message. The Middle Ages are presented as a period of time guided by a religious mentality and an economical and social praxis that hid the Utopia which reappeared in the Humanism and in some Evangelizing practices in the New World.

\section{Key words}

Christian social utopia, mentality, history, crisis, Middle Ages.

Contrariamente a su uso en el lenguaje común como sinónimo de quimera, ilusión o fantasía, en este artículo se utilizará el término utopía con el sentido de motor histórico. Se asumirá que es posible conocer más al hombre de una determinada época si se conocen sus utopías, "ya que es la consecución de sus utopías la que hace que el hombre de una época concreta actúe de una determinada forma, intentando mejorar su realidad presente para alcanzar un futuro mejor”2.

La anterior afirmación se fundamenta en los datos de la antropología filosófica según los cuales la historia de la humanidad ha sido la historia del hombre en busca de la realización de un "buen lugar o lugar feliz" en su contexto propio; ese proyecto y los esfuerzos por hacer del mundo un lugar más habitable es lo que se ha llamado utopía, y ésta, como categoría filosófica tiene la virtud de revelarnos que el ser humano ha necesitado, para dinamizar su existencia, de la formulación de sus sueños y aspiraciones más profundos, y la seguida construcción de esos sueños en su presente inmediato.

Al intentar comprender al pensador medieval y su contexto vital, lo hacemos desde la metodología de la historia de las ideas que estudia la mentalidad de un determinado contexto histórico y que se configura según Zubiri como "modos comunes y habituales de pensar que han ido quedando objetivados en el cuerpo de la sociedad y que se transmiten de generación en generación”3. Tal metodología nos permitió descubrir que la realidad utópica presente en la Edad Media no se entiende sino desde su contexto inmediatamente anterior, y es desde la utopía social cristiana que abre un horizonte claro de comprensión para interpretar la praxis de la Iglesia y sociedad medieval como herederos de tal utopía.

\section{1. antecedentes}

\subsection{Jesús de Nazareth y la recuperación de la utopía semita}

En este aparte pretendemos analizar el cristianismo, es decir, el movimiento de Jesús de Nazareth, desde la óptica de la utopía, para descubrir a qué nos estamos refiriendo cuando utilizamos el término utopía social cristiana.

\footnotetext{
Beatriz Fernández Herrero, La utopía de América (Barcelona: Anthropos, 1992), p. 15.

3 Germán Marquínez Argote, “Aportes de Zubiri al concepto de mentalidad”, Ideas y mentalidades (Bogotá: El Búho, 1996), p. 36.
} 
Cuando Jesús de Nazareth nace entre el 6-7 a.C. y el 30 d.C., se encuentra con una religión judía, heredera de la tradición semita, que por causas históricas ha radicalizado su Ley y espera a un Mesías de carácter político que habría de devolver a Israel la tierra y el control de Palestina, que en ese entonces estaba bajo dominio romano.

El centro de interés de los diversos grupos judíos del siglo I fue la Ley y el Templo. Efectivamente la Ley, desde la época de los Macabeos, incluso en la diáspora, fue considerada como la constitución fundamental del pueblo judío, expresión de su alianza con Dios. El Templo de Jerusalén, centro de las grandes fiestas, era el símbolo concreto de la unidad del pueblo de Israel (...). La religión judía de la Palestina del siglo I era por tanto la religión de la Ley y el Templo ${ }^{4}$.

Según Giuseppe Segalla en su obra Panoramas del Antiguo Testamento, los judíos conformaban grupos que tomaban diversas actitudes frente al control ejercido por los romanos: los saduceos y los esenios, a pesar de pertenecer ambos a la clase sacerdotal, habían escogido dos caminos; los primeros habían aceptado el compromiso político y los segundos renunciaron radicalmente a todo trato, retirándose al desierto y formando una secta de hombres puros, alejados de la vida de cada día. Los fariseos escogieron más bien un camino medio; aceptaron el reto de la vida cotidiana, en el mundo helenizado, pero intentando conservar su identidad religiosa.

Desde el análisis del judaísmo encontramos, entonces, que la utopía judía (en la que construían el presente a partir de lo que esperaban que fuera el futuro), en el ámbito político era la espera de un Mesías libertador que los sacaría de la realidad marginal en que se hallaban frente al Imperio Romano.

En el aspecto religioso existía una expectativa de orden sacerdotal:

Esta expectación [religiosa] se acentuaba en determinados grupos, cosa que sabemos con toda seguridad en el caso de la comunidad de Qumrán ${ }^{5}$, que esperaba la venida de un gran profeta y del “ungido de Aarón y de Israel” (1 Qs IX $10-11)^{6}$.

Con esto observamos que el judaísmo esperaba dos Mesías: uno que restablecería la estabilidad política, y otro, un "pontífice escatológico”, que debería llevar la institución sacerdotal a su plenitud. Esta utopía sería cumplida por Dios por la observancia exacta y minuciosa de la Ley judía (cultual y ritual), es decir que la concreción histórica de la utopía está referida a la fidelidad a la Ley en sus distintos mandatos y prescripciones, que juntos sobrepasaban las seiscientas normas.

Giuseppe Segalla, Panoramas del Nuevo Testamento, 3 ed. (Pamplona: Verbo Divino, 2000), p. 91.

Entre 1946 y 1956 se descubrieron unos pergaminos escritos en hebreo, arameo y griego de gran trascendencia histórica junto a las ruinas de Qumrán, región situada al noroeste del mar Muerto. El conocimiento de los textos produjo inicialmente una fuerte conmoción en el mundo cristiano, al observar las profundas afinidades entre el mensaje de Jesús y la doctrina de la "comunidad de Qumrán”. Esta comunidad era un grupo radical escindido del importante movimiento judío disidente de los esenios. Entre las razones de la escisión cabe citar: el papel del Templo, cuestiones relativas al calendario festivo, concepciones enfrentadas de la escatología e ideas en torno a la elección de los justos. Véase: Juan José Tamayo Acosta, Hacia la comunidad, Vol. 5., pp. 25-26.

6 José María Castillo, Símbolos de libertad, 5 ed. (Salamanca: Sígueme, 1992), pp. 60-61. 
Si Jesús de Nazaret históricamente fue sentenciado a morir en una cruz por la institución religiosa judía y civil romana, quiere decir que Él no se movió y no estaba motivado por esa utopía judía. Entonces, nos surge un interrogante vital en nuestro camino investigativo: ¿cuál es la utopía de Jesús?

Partamos de que, para reconocer la utopía, lo que mueve a alguien a una acción concreta, es necesario analizar el comportamiento de ese alguien y situarlo en su contexto vital, ya que el comportamiento, la manera de estar en el mundo, es el libro abierto en el que leemos el motor que mueve a un ser humano a obrar de determinada manera, motor que, como señalamos anteriormente, es lo que denominamos aquí utopía. "Es la consecución de sus utopías lo que hace que el hombre de una época concreta actúe de una determinada forma, intentando mejorar su realidad presente para alcanzar un futuro mejor"'.

Las acciones de Jesús se sitúan en un marco ético-comunitario, distinto al horizonte legalista y cultual judío. Su movimiento busca la igualdad social y religiosa y se rige por el principio de misericordia, abierta no sólo a los elegidos (como se sentía el pueblo judío), sino a todos los seres humanos, con especial predilección por los pobres, como primeros destinatarios del mensaje de Jesús.

El término "pobres" debe ser entendido en una doble línea; la primera hace referencia a aquellos que gimen bajo algún tipo de necesidad básica (Is 61, 1), como los hambrientos o los sedientos, los forasteros, etc; en otra línea, pobres son aquellos que son despreciados por la sociedad vigente, los tenidos por pecadores, los publicanos, las prostitu- tas, etc. En este sentido, "pobres" son aquellos que ejercen profesiones despreciadas. Como lo afirma el teólogo Joachim Jeremías:

Los seguidores de Jesús consistían en personas difamadas, que gozaban de baja reputación y estima: los incultos, los ignorantes, a quienes su ignorancia religiosa y su comportamiento moral les cerraban, según las convicciones de la época, la puerta de acceso a la salvación (...). Si contemplamos a esas mismas personas con los ojos de Jesús, las vemos a una luz distinta. Jesús las llama "los pobres", "los fatigados y agobiados por el peso” (Mt 11, 28) (...) su peso es doblemente agobiador: abarca tanto el desprecio público de que eran objeto por parte de los hombres, como la falta de perspectiva de hallar jamás salvación en Dios.

El anuncio que hace Jesús de una manera nueva de relacionarse con Dios y con los demás es para aquellos, como señala Alberto Ramírez ${ }^{9}$, que viven en el desprecio y la marginación, aquellos que viven bajo la opresión, para quienes la vida no ofrece un horizonte claro de posibilidades. Esta utopía de Jesús de carácter social, que busca restablecer al ser humano de lo que le impide ser plenamente hombre y mujer (opresiones, en lenguaje religioso, pecados, injusticias en nombre de Dios y del Estado), se enfrenta con la religión judía y su carácter ritual.

Jesús arremete contra la pureza ritual, contra el Templo y la Ley que eran los pilares para una sociedad judía en la que la misericordia era un acto segundo. Jesús contrasta visiblemente esta óptica cuando afirma, recordando al profeta Oseas $(6,6)$ : "Miseri-

\footnotetext{
Fernández Herrero, La utopía..., p. 15.

Joachim Jeremías, Teología del Nuevo Testamento, 2 ed., Vol 1 (Salamanca: Sígueme, 1974) pp. 137-138.

Alberto Ramírez Téllez, iEl Reino de Dios está cerca!, Optantes (Bogotá) 12-13 (1991), p. 5.
} 
cordia quiero y no sacrificios" (Mateo 9, 13; 12, 7). Allí Él se refiere a que Dios (a quien Jesús llama Padre) prefiere la bondad hacia los demás, y relativiza las prácticas cultuales que se realizaban en el Templo. "Al recordar estas palabras proféticas, Jesús viene a decir que entre dos modos de relacionarse con Dios, uno con ritos, el otro mediante las relaciones humanas, Dios mismo prefiere el segundo, porque por encima de los ritos Él quiere la bondad para con los demás”10.

Cuando se hace presente en el Templo de Jerusalén, lo hace para desenmascarar la situación de desigualdad que existía entre las clases dirigentes del Templo y las personas sencillas que acudían a él. La escena bíblica de la expulsión de los comerciantes del templo (Mateo 21, 12-17) fue la acción decisiva de su comportamiento que hizo que los dirigentes judíos procedieran contra Él y lo acusaran de hereje y de revolucionario hasta acabar con su vida; sumado esto a otros conflictos que se le presentaron con las autoridades judías por perdonar pecados, comer con pecadores, no ayunar, y arrancar espigas y curar personas en sábado. Actos estos que iban en contra de la Ley judía y que anunciaban un nuevo orden de cosas en Jesús.

Todo su anuncio, además, lo hace con compañía; elige un grupo reducido de personas (discípulos) para que le acompañe, y lo instruye detalladamente. Es decir, Jesús no es un hombre solo, sino que con su manera de ser funda las bases para un vivir en comunidad y en relación con los otros.

¿Qué movía a Jesús a obrar así? En los Evangelios hay una expresión que nos puede aportar la respuesta a este interrogante; Jesús se presenta como el Hijo de Dios que no ha venido a abolir la Ley, sino a darle plenitud:
"No penséis que he venido a abolir la Ley y los Profetas. No he venido a abolir, sino a dar cumplimiento" (Mateo 5, 17). Por lo anterior, deducimos que no se refiere a la Ley actual judía: por su comportamiento y sus referencias al Antiguo Testamento, descubrimos que se está refiriendo a la utopía social semita del pueblo de Israel.

Esta es precisamente la utopía social que Jesús plenifica y que vivencia concretamente en el ambiente judío y no judío: que es posible la construcción de una sociedad que sea a imagen de una comunidad de hermanos, iguales, donde todos estén en función de los demás, donde no haya marginados y donde esta forma de vida incluya también a los pobres; desde aquí se comprende la vida y las acciones de Jesús desde la utopía que lo movía a obrar.

Entre los años 80 y 90 d.C. se escribe el libro de los Hechos de los apóstoles, en el que se describe la vivencia de los primeros cristianos (Hch 2, 42-47); vivían unidos con un corazón y una sola alma, todo lo tenían en común y nadie pasaba necesidad. Posiblemente esta descripción es una relectura del libro del Deuteronomio, y promueve la vivencia y compromiso personal de hacer vida esa utopía ${ }^{11}$, al estilo del pueblo de Israel y de Jesús; es decir, que el hombre es un ser incondicional hacia el otro y que esta actitud es posible gracias a que se tiene una profunda experiencia de gratitud por lo que se reci$b e, y$ a que se siente a los otros como hermanos, como parte de una sola familia, la familia que Israel experimentó y entendió como aquello que Dios mismo deseaba.

A partir de lo anterior se pueden entender los planteamientos que a continuación haremos describiendo el ocaso de la utopía so-

10 Castillo, Símbolos..., pp. 61-62.

11 Las utopías se escriben para señalar que en el presente urge asumir determinadas actitudes o estilos de vida, para pasar a la dimensión de la concreción de la utopía. 
cial cristiana en la Edad Media, y su posterior florecimiento a través del humanismo, especialmente en el inglés Tomás Moro y en su obra Utopía, tema este último que desborda el presente artículo.

\section{La edad media desde la crisis de la utopía cristiana y la conformación de la iglesia institucional}

En el apartado anterior señalamos que la utopía cristiana es eminentemente social, pues busca la igualdad, la fraternidad, la solidaridad, la libertad, con preferencia por los marginados. En este apartado se analizará el curso histórico del movimiento de Jesús, concretado en la Iglesia durante la Edad Media (313-1492). Se tendrán en cuenta dos aspectos esenciales: la praxis eclesial y la mentalidad con la que se configuró este periodo de tiempo, respondiendo a los siguientes interrogantes: ¿cómo se vivió en esta época la utopía social cristiana de una sociedad igualitaria? ¿Respondió la Iglesia, heredera del pensamiento de Jesús, el Cristo, a su utopía?

Entre el 33 y el 313 d. C. encontramos un movimiento cristiano liderado por quienes eran conocidos como apóstoles, continuadores de la causa de Jesús, que invitaban a seguir el ejemplo del mártir de Nazareth que había muerto anunciando que era posible la construcción de un nuevo orden social. El profesor José Uriel Patiño, en su libro sobre historia de la Iglesia, afirma que la descripción que hace el libro de los Hechos de los apóstoles muestra lo que se pretendía que fuera el movimiento de Jesús:

La comunidad que presenta el libro de los Hechos de los Apóstoles, es un ideal que pocos realizaron, (...) todos los creyentes vivían unidos y tenían todo en común; vendían sus posesiones y sus bienes y lo repartían entre todos, según la necesidad de cada uno (Hch 2, 44-45) (...), máxime cuando existían grandes diferencias que no permitían la auténtica comunión y cuando los primeros cristianos siguieron cumpliendo la ley mosaica; de ahí que el Evangelio insista en los “pobres de espíritu”12.

Sin embargo, Pablo de Tarso (martirizado en el 64 d.C., aprox.), en sus cartas insiste a las comunidades cristianas ya constituidas, y principalmente a las fundadas por él mismo, lo fundamental del mensaje de Jesús, en tiempos en que la división y los falsos mensajes son lo cotidiano. Por citar un ejemplo, en la carta que Pablo dirige a la Iglesia de Roma ${ }^{13}$ hace un llamado a vivir la caridad sin fingimiento, compartiendo las necesidades de los hermanos, en constante práctica de la hospitalidad. Son palabras que responden al contexto de la Iglesia de Roma golpeada por la persecución externa del Imperio y la división interna, suscitada por dos bandos: los paganos convertidos al cristianismo y los venidos del judaísmo.

12 José Uriel Patiño, Historia de la Iglesia: la Iglesia: comunidad e institución, protagonista de la historia, Vol. I (Bogotá: San Pablo, 2001), p. 33.

13 "Pablo de Tarso, cuando utiliza el término Iglesia, da a entender que ya se ha logrado un cierto grado de identidad cristiana que lleva a evitar el uso del término 'sinagoga', término universalmente empleado por los judíos para designar el lugar de reunión como la asamblea en cuanto tal de los que se congregaban el sábado para el culto (...). Si Pablo emplea el término (åêeeecçóßá), tal vez no quiere decir que sólo cuando se reúnen los cristianos para el culto realizan la Iglesia de Dios, sino que en toda circunstancia la están realizando". Silvestre Pongutá, San Pablo: 1 Tesalonicenses 1, 1 Corintios 1, Colección Apuntes (Bogotá: Centro Editorial Javeriano, 2003). 
Los Evangelios, que se escribirían a partir del año 70, consignan lo que debería ser la identidad de la comunidad cristiana y de todo seguidor de Jesús, y promueven que cada hombre y mujer de la historia reproduzca su obrar, su experiencia de Dios, en una palabra, su utopía: la construcción de una sociedad igualitaria, sin distinciones de hermanos, que mueve a los creyentes a estarse entre los marginados y perdidos de la sociedad.

En estos tres primeros siglos del movimiento cristiano se resalta que los cristianos vivían en un ambiente poco propicio para su desarrollo y extensión, y la puesta por escrito de la vida de Jesús en lo que hoy conocemos como Evangelio, se hizo para promover y sostener un comportamiento y actitud frente a la existencia que mantuviera la utopía cristiana, contra el ambiente hostil circundante.

Es propio también de todos los tiempos de crisis de las culturas construir relatos donde se muestre el pleno funcionamiento de la utopía para animar en el presente su trabajo, y para construirla y verla realizada plenamente.

Dar muestras de ese cumplimiento de la utopía de Jesús fueron los esfuerzos de las primeras comunidades cristianas de estos primeros siglos: sin embargo, "Entre las mejores muestras de vida moral [que presentaron estas comunidades] se citan: el matrimonio, la familia y la beneficencia, que se convirtió en la primera preocupación de la Iglesia cristiana por la cuestión social”"14. Es claro que en este tiempo las comunidades cristianas (Iglesia) adquirían un rostro organizativo establecido para que todos sus miembros se movieran al servicio. En el libro de los $\mathrm{He}$ chos de los apóstoles $(20,34)$, se refleja lo anterior cuando afirma: "En todo os he enseñado que es así, trabajando, como se debe socorrer a los débiles y que hay que tener presentes las palabras del Señor Jesús, que dijo: 'Mayor felicidad hay en dar que en recibir'”.

Este movimiento de Jesús de Nazaret, que era considerado una secta judía, sufrió la persecución. Sólo hasta el año 313, cuando el emperador Constantino con el edicto de Milán declara la libertad religiosa para todos los habitantes del Imperio, la tolerancia oficial trajo un nuevo rumbo para la historia de la Iglesia naciente: a los cristianos se les devolvían las posesiones que por causa de su culto se les habían expropiado; pero el momento más significativo se da en el 380 cuando el emperador Teodosio eleva al cristianismo a la categoría de "religión oficial del Imperio". Detengámonos en los primeros años de la persecución de la Iglesia para rastrear el impulso utópico de los seguidores de Jesús.

Entre el 380 y el transcurso de la Edad Media, encontramos una situación particular: esas comunidades cristianas organizadas para el servicio y en un contexto de persecución, con el cese de violencia hacia ellas, adquieren un nuevo estatus dentro del Imperio Romano; sus dirigentes serán ahora quienes en materia política y religiosa llevarán los lineamientos del Estado. De una organización que buscaba la igualdad pasará a ser una institución que promueve sus propios intereses y los del Estado que representa -mayor territorio, eliminación de sus enemigos, etc.-, ahogando con ello la utopía, es decir, su razón de ser y sus búsquedas en la sociedad.

14 Pongutá, San Pablo..., p. 94. 
A juicio de Jacques Le Goff, destacado historiador del medioevo, con las invasiones bárbaras de los siglos III al VI y el desorden social provocado por éstas, los obispos y monjes se convertían en jefes polivalentes de un mundo desorganizado: a su papel religioso habían añadido un papel político al negociar con los bárbaros; económico al distribuir víveres y limosnas; social, al proteger a los pobres de los poderosos; incluso militar, al organizar la resistencia o al luchar “con las armas espirituales” allí donde ya no había armas materiales:

Al no haber otro remedio, habían aceptado los métodos del clericalismo, de la confusión de poderes. Intentan, mediante la disciplina penitencial, mediante la aplicación de las leyes canónicas (el comienzo del s. VI es la época de los concilios y de los sínodos paralelamente a la codificación civil), luchar contra la violencia y suavizar las costumbres ${ }^{15}$.

La crisis de la utopía social cristiana se hace visible, con mayor claridad, ya que la Iglesia, representada en el Papa y sus clérigos, se mueve en la búsqueda de sus intereses particulares; mediante donaciones hechas por los reyes y poderosos, incluso por los más humildes, acumula tierras, rentas, en una sociedad donde la acumulación de riquezas supone el empobrecimiento de muchos debido a la escasa producción del sistema feudal.

(...) sus obispos, que pertenecen casi todos a la aristocracia de los grandes propietarios, son omnipotentes en sus ciudades, en sus circunscripciones episcopales e intentan serlo también en el reino. Finalmente, al intentar servirse los unos de los otros, reyes y obispos se neutralizan mutuamente y se paralizan: la Iglesia intenta dirigir el Estado y los reyes gobernar la Iglesia ${ }^{16}$.

Con el control del Mediterráneo por parte del Islam en el siglo VII, Europa occidental acentuó su carácter agrícola, dando como resultado que toda la existencia social recayera sobre la posesión de la tierra; quien poseyera la tierra era rico y quien trabajara en ella era pobre. Encontramos entonces una sociedad de pocos señores y muchos siervos, quienes trabajan la tierra y pagan tributos a su dueño. Con la acumulación de tierra por parte de la Iglesia ésta se enriqueció de tal manera que en lugar de estar del lado de los “marginados” para sacarlos de su estado y de la realidad de explotación en la que se encontraban, los adquirió para su servicio; de tal manera que, al protestar los siervos por tales condiciones, se convirtieron en enemigos de la Iglesia.

La Iglesia cristiana medieval sucumbió a los peligros que tiene todo lo institucional, y esto es, como afirma Walter Kasper, el peligro de la “petrificación institucional”, del poder, la manipulación y el mal uso propio del peso de los intereses institucionales. Del organizarse para servir mejor, para acoger a todos y llegar a ser comunidad de hermanos unidos por la fe, a la manera de Jesús de Nazareth, encontramos una Iglesia medieval institucionalizada, alejada de la utopía social de Cristo; con imágenes de Él que, más que invitar a los seres humanos a hacer de la sociedad el "paraíso perdido”, obligaban a preparar la existencia con penitencia y "olvido de sí mismo” para ganar y encontrar la vida futura, "la ciudad de Dios”, "la eternidad”.

15 Jacques Le Goff, La civilización del Occidente medieval (Barcelona: Paidós, 1999), p. 39.

16 Le Goff, La civilización..., p. 40. 
A la Iglesia medieval con respecto a la utopía de Jesús le sucedió el gran peligro de las instituciones:

(...) que la verdad se funcionalice y relativice en interés de la supervivencia tanto del individuo como del "sistema" social. Más concretamente: que Jesucristo sea encasillado eclesiásticamente y que la Iglesia ocupe el lugar de Jesús. La Iglesia en tal supuesto, ya no anuncia ni da testimonio de Jesucristo, sino que actúa como defensora y testigo de sí misma ${ }^{17}$.

Cabe anotar que también contribuyó al imaginario económico de la Iglesia, que sintetiza muy bien Henri Pirenne en su libro Historia económica y social de la Edad Media, el hecho de que el único fundamento del orden social era la tierra; la Iglesia la concebía como un bien dado a los hombres "para ponerlos en posibilidad de vivir en este mundo pensando en la salvación eterna”; de allí que el fin del trabajo no era enriquecerse, sino mantenerse en la condición en que cada cual ha nacido, hasta que de esta vida mortal pase a la eterna; la renuncia del monje se consideraba el ideal hacia el cual debía dirigir la mirada toda la sociedad. Tratar de hacer fortuna era caer en el pecado de avaricia; de allí que la pobreza es de origen divino y de orden providencial; pero correspondía a los ricos aliviarla por medio de la caridad, de la que los monasterios debían dar ejemplo; desde esta perspectiva entendemos el por qué la Iglesia no puso en tela de juicio las "diferencias de clases" sino que se interpretaron como expresión del orden divino:

Vivir con los pobres o como los pobres no fue ideal en aquella época, ni para la nobleza temporal ni para los obispos, abades o clero, ni siquiera para los monjes a los que se había designado desde tiempos antiguos como pauperes Christi (pobres de Cristo). Ellos debían ser abogados de los pobres. Por ellos al monasterio se le habían encomendado muchas tareas sociales y caritativas. Los monjes hablaban a la conciencia de los poderosos no para protestar contra el "sistema", sino para confirmarlo y poder así ayudar a los desamparados y afligidos en la salvación de sus almas ${ }^{18}$.

Sin embargo, los monasterios, con el paso del tiempo cayeron en la misma falta que combatían: ellos junto con los obispos se dedicaban a vivir de las rentas y prestaciones de los dominios de los cuales disponían; en el transcurso del siglo XIII los monjes, tan queridos en sus inicios, habían perdido su prestigio y se les pagaba el diezmo con repugnancia; en una sociedad cuya población agrícola vivía de la servidumbre, los monasterios tenían a su disposición innumerables sirvientes; con un cuadro así se unían con toda la Iglesia a la inequidad existente y a la producción de desigualdad y miseria que encontramos en la Edad Media.

Desde la llamada Reforma Gregoriana iniciada a finales del siglo XI y comienzo del XII, la Iglesia había empezado un camino de renovación que la llevaría a replantear sus relaciones con el mundo y con el poder institucional; la libertad de la Iglesia fue el objetivo principal de esta reforma iniciada por el Papa Gregorio VII (1073-1085), quien concebía, junto con los reformadores que le siguieron, que la dirección de la Iglesia por la monarquía equivalía a una usurpación e inversión del orden divino, con lo cual la

17 Walter Kasper, Jesús el Cristo, 9 ed. (Salamanca: Sigúeme, 1994), p. 30.

18 Isnard W. Frank, Historia de la Iglesia medieval, Biblioteca de Teología 11 (Barcelona: Herder, 1988), p. 89. 
Iglesia había sido utilizada en una servidumbre que obstaculizaba su misión en el mundo. Se intentó regresar al modelo de la Iglesia antigua.

Este esfuerzo le permitió desempeñar un papel muy importante en la difusión de la cultura (ella detentaba la lectura y la escritura), el arte y una gran organización institucional. A pesar de ser una autoridad moral y financiera, no pudo detener, por los intereses económicos del momento, los fuertes enfrentamientos de los siglos XIII-XV de los campesinos y comerciantes, contra la nobleza y ella misma, por las difíciles situaciones económicas y sociales en que se encontraban revueltas que se explican por la insistencia de mantener un orden social feudal en una sociedad donde el desarrollo de la industria y del comercio estaban trosformando profundamente el espíritu y la propia existencia de la sociedad:

El descontento social pudo haber sido causado por el exceso de miseria como por la voluntad de poner fin a un estado de cosas que chocaban tanto más cuanto que se creía poseer fuerza para cambiarlo (...). La servidumbre durante el s. XIV en todos los lugares en que se había conservado, se tornaba tanto más odiosa cuanto que, siendo ahora una excepción, cobraba la apariencia de una humillación ${ }^{19}$.

También es necesario descubrir la mentalidad que en materia religiosa estuvo presente en este momento histórico para encontrar más luces para responder el siguiente interrogante: ¿respondió la Iglesia, heredera del pensamiento de Jesús, a su utopía?
Durante el periodo de dominación bárbara, especialmente en la decadencia de la monarquía merovingia y del clero franco, se afianza en la Iglesia la mentalidad de desprecio del mundo y de desvinculación de lo terreno; pensamiento que dirigirá la concepción religiosa de lo restante de la Edad Media.

Durante un brote de peste negra, por ejemplo, en Roma, el Papa Gregorio Magno (590604) piensa que las calamidades anuncian el fin del mundo, y para él el deber de todo cristiano es hacer penitencia, desligarse de la realidad presente para prepararse a lo que se avecina. No piensa en extender la cristiandad, en convertir, ya se trate de los anglosajones o de los lombardos, si no es para desempeñar mejor su papel de pastor a quien “el Cristo del juicio final” pedirá constantemente cuenta de su rebaño; los modelos que propone en su obra de edificación espiritual son San Benito, es decir, la renuncia monástica, y Job, es decir, la renuncia integral y la resignación. En uno de sus sermones afirma:

Para qué continuar recolectando cuando el que recolecta va a desaparecer. (...) Extirpemos de raíz nuestras malas costumbres, arrancándolas, no sólo de nuestro obrar, sino también de nuestro afecto. Que no nos aparten del convite eterno ni los deseos carnales, ni las preocupaciones absorbentes, ni el fuego de la ambición, sino que las cosas que hacemos en este mundo, aun las que son honestas, hagámoslas como de pasada, y así las cosas terrenales que nos causan placer de tal manera serán una ayuda para nuestro cuerpo que no obstaculizarán a nuestro espíritu ${ }^{20}$.

19 Henri Pirenne, Historia económica y social de la Edad Media, 11 ed. (Fondo de cultura económica, 1986), p. 89.

20 Gregorio Magno, “De las homilias de san Gregorio Magno, papa, sobre los Evangelios”, Liturgia de las horas, Vol. I (Barcelona: Credograf), p. 1289. 
Esta mentalidad hizo carrera, ya que ante los problemas suscitados por la politización de la Iglesia, hubo cristianos que "se alejaron de la sociedad” para vivir más radicalmente lo escrito en los Evangelios; querían en sus lugares de residencia crear un modelo de vida que contrastara con la sociedad establecida y con la Iglesia de su momento. La utopía social cristiana se concretaría en pequeñas iniciativas de hombres y de mujeres que tanto en Oriente como en Occidente deseaban vivir como hermanos.

Un ejemplo de lo anterior lo encontramos en Agustín de Hipona (354-430), quien quiso concretar el seguimiento de Jesús en hombres que vivieran juntos "en una sola alma y un solo corazón”. En la regla de vida que escribió para ellos encontramos lo siguiente: "Lo primero porque os habéis congregado en comunidad es para que habitéis en la casa unánimes y tengáis una sola alma y un solo corazón (...) y no tengáis cosa alguna como propia, sino que todo sea de todos; $y$ el superior distribuya a cada uno de vosotros su alimento y el vestido, no igualmente a todos porque no tenéis todos iguales fuerzas, sino a cada uno según su necesidad”21.

La dificultad de estas empresas estriba en que quien no estaba dentro de estos "monasterios” y no era una especie de "asceta” o "santo”, era visto como “amigo del mundo” y, por lo tanto, lejano de Dios.

La obra principal de Agustín, La ciudad de Dios, presenta esa dinámica; una ciudad construida por los hombres, hecha por el egoísmo, y otra, la “ciudad de Dios”. Los monasterios, entonces, eran considerados como pequeñas fortalezas donde habitaba Dios, y el mundo era visto como un "valle de lágrimas” en el cual el hombre se encuentra expiando sus pecados; entre más sufra, más se santifica; entre más castigue el cuerpo mortal, habrá más posibilidad de ganar la vida inmortal; donde resignarse y esperar son las actitudes básicas del creyente; donde la riqueza y la pobreza son vistas como venidas de Dios, y la primera es administrada sabiamente por los eclesiásticos, que la acumulan para que no haga daño a la gente, ya que el dinero corrompe y aparta de la posibilidad de ganar el cielo.

En la segunda mitad del siglo XI, se constata en la Iglesia una vuelta a la vida de Jesús, sobre todo a su pasión; a la piedad mariana, cuyos promotores principales fueron Anselmo de Canterbury (†1109) y Juan de Fécamp (†1078), y cuyo gran impulsor fue Bernardo de Claraval (1090-1153):

Si en los albores de la edad media hubo interés, por ejemplo, en enumerar en largas fórmulas de oración y confesión las sagradas propiedades de Dios así como los defectos y pecados del hombre, ahora este mismo tema había adquirido un tono más efectivo y reflexivo. Las fórmulas de evocación protectora aparecían en forma de sentencias de piedad reflexiva ${ }^{22}$.

Fue la devoción a Jesús la que configuró la piedad de finales de la Edad Media; ahora se hablaba de "imitación de Cristo", que condujo hacia los pobres, entendidos aquí como los carentes de cosas materiales y físicas. En ellos se contemplaba a Jesús en cuya ayuda corrían personas piadosas; la pobreza, humildad y penitencia, junto a la contemplación de la pasión, se convirtieron en el ideal de santidad de este tiempo. Lo positivo fue que

\footnotetext{
21 Regla de vida de la Congregación de los Agustinos de la Asunción, "Fin y fundamento de la vida común”, Nº 3 y 4 (España: Ed. Santa Rita, 1985), pp. 9-10.

$22 \quad$ Frank, Historia..., p. 169.
} 
esta mentalidad desembocó en un humanismo religioso, cultural y renovador que, en oposición de la Iglesia institucional, desplegó su propio vuelo en grandes humanistas que veían en el hombre la mayor obra de Dios, y que se interesaron por sus condiciones terrenales, preocupados por una mayor equidad y bienestar para el ser humano.

La anterior mentalidad también tuvo su lado negativo, ya que invitaba a la resignación de la persona ante su situación social. Cualquier protesta era vista como un ir en contra del orden divino; el Cristo sufriente y humillado era el ideal; tal mentalidad se popularizó debido a la cantidad de autores que escribían sobre ella, entre los cuales citamos al monje alemán Tomás de Kempis (1379-1471), cuyo famoso libro fue editado por primera vez en 1452, cuarenta años antes del descubrimiento de América, y que contiene principalmente el camino espiritual del autor apoyado en el pensamiento de San Bernardo de Claraval y de San Agustín de Hipona; camino que exigía a los creyentes estar en una constante búsqueda de Dios por las vías de la penitencia y la mortificación. El Libro II, 1-6, es una ilustración de este pensamiento: "Conviértete a Dios de todo corazón, despréndete de este mundo miserable y tu alma encontrará la paz, pues el reino de Dios es paz y alegría”23.

\section{A manera de conclusión}

La práctica eclesial y social dada en el periodo medieval se entiende a la luz de una mentalidad religiosa que se constituyó en contravía de la utopía social cristiana expuesta en este artículo. Tal mentalidad sustentaba una praxis eclesial interesada en la devoción interior a Jesús, sin un claro compromiso hacia la igualdad y justicia entre sus fieles, y que juzgaba importante que todos pertenecieran a la Iglesia para ser salvados ${ }^{22}$. En el Renacimiento, siguiendo el desarrollo de las ideas utópicas cristianas, tal mentalidad chocará con el resurgir de la utopía social cristiana, cuyo tinte humanista estaba interesado en los hombres americanos y su desarrollo, al considerar al hombre como la mayor obra de Dios.

Entonces, ante la imposibilidad de la concreción de la utopía social cristiana en Europa en el periodo medieval, y aun renacentista, debido a la praxis institucional de la Iglesia de enriquecimiento exagerado y de estar al lado del poder político buscando sus propios intereses (de expansión y de dominación), y con el descubrimiento del Nuevo Mundo y el impulso dado por los renacentistas, América será vista como el lugar apropiado para la realización de la utopía cristiana, surgiendo relatos utópicos en Europa como los de Moro, Campanella y Bacon; y experiencias utópicas en América, sustentadas por las Leyes de Indias y la práctica evangelizadora de algunos misioneros; recordemos la de la Compañía de Jesús en las reducciones fundadas por ella en el Paraguay, y de otras misiones que intentaron implantar la utopía cristiana en nuestro continente, lejos del poder dominante ahogado en su búsqueda incesante de dominio e intereses propios ${ }^{24}$.

23 Thomas Kempis, Imitación de Cristo, Libro II, pp. 1-6.

24 Aquí se juzga importante anotar la idea de la Iglesia de la consecución de un orbe cristiano, según la cual su labor primera era evangelizar a los "infieles” y anunciarles la verdad de Jesucristo por la vía incluso del sometimiento mediante la violencia; las Cruzadas y la Inquisición son prueba de este pensamiento. Quien fuera en contra de la Iglesia a nivel personal o estatal era castigado por alguna de aquellas instituciones, y esa era también la labor de los príncipes, ayudar a la consecución de este orbe cristiano. 